\section{Original Article}

Korean J Transplant 2021;35:77-85 https://doi.org/10.4285/kjt.21.0006
Received April 16, 2021

Revised June 16, 2021

Accepted June 21, 2021

Corresponding author: Jongwon $\mathrm{Ha}$ Department of Surgery, Seoul National University Hospital, 101 Daehak-ro, Jongno-gu, Seoul 03080, Korea

Tel: +82-2-2072-2991

Fax: +82-2-2766-3975

E-mail: jwhamd@snu.ac.kr

(c) The Korean Society for Transplantation This is an Open Access article distributed under the terms of the Creative Commons Attribution Non-Commercial License (http://creativecommons.org/licenses/ by-nc/4.0/) which permits unrestricted non-commercial use, distribution, and reproduction in any medium, provided the original work is properly cited.

\section{$\mathrm{KJT}^{\mathrm{K}}$ \\ KOREAN JOURNAL OF TRANSPLANTATION}

\title{
A study on the performance of the Donation Improvement Program in Korea
}

\author{
Su Jin $\mathrm{Heo}^{1}$, Yong Ho Ju${ }^{1}$, Eun Jeong Noh${ }^{1}$, Kyoung Min Kim¹, Yu Kyoung Son ${ }^{1}$, \\ Sun Woo Jung ${ }^{1}$, Hyun Jin Kang ${ }^{1}$, Jung Rim Lee ${ }^{1}$, Won Hyun Cho' ${ }^{1}$, Jongwon Ha ${ }^{2,3}$ \\ ${ }^{1}$ Korea Organ Donation Agency, Seoul, Korea \\ ${ }^{2}$ Department of Surgery, Seoul National University College of Medicine, Seoul, Korea \\ ${ }^{3}$ Transplantation Research Institute, Medical Research Center, Seoul National University College of Medicine, \\ Seoul, Korea
}

Background: The Donation Improvement Program (DIP) is intended to increase organ donation at hospitals. The program includes education for healthcare professionals of participating hospitals about each step of donation as well as evaluation. The DIP consists of medical record review (MRR) and a Hospital Attitude Survey (HAS). The purpose of this study was to evaluate the DIP results for the last 7 years.

Methods: For MRR, we analyzed 58,385 cases of mortality from 77 hospitals between 2012 and 2018. The HAS data for the degree of education experience, competence, and knowledge related to brain death (BD) and donation were analyzed from 23 DIP-participating hospitals in 2012 and 51 DIP-participating hospitals in 2015 and 2018 each.

Results: The recognition rate of potential BD was $24.9 \%, 61.3 \%$, and $73.2 \%$, and donation rate was $7.5 \%, 11.7 \%$, and $15.8 \%$ at 6 months before, $1-2$ years after, and $4-5$ years after the agreement, respectively. Hospital staff with the necessary competence or knowledge to explain BD constituted $44.0 \%$ in 2012 , while this increased to $62.8 \%$ in 2018 .

Conclusions: The DIP could increase the recognition of $\mathrm{BD}$ and the organ donation rate, and positively affect the attitudes of healthcare professionals toward organ donation. Spreading the DIP to all hospitals is urgent to increase organ donation.

Keywords: Donation Improvement Program; Donor action program; Medical record review; Hospital attitude survey; Organ and tissue donation; Transplantation

\section{INTRODUCTION}

In Korea, brain death is recognized as death only in the case of organ donation. This is a major inhibitor of organ donation after brain death in Korea. The number of braindead organ donors decreased rapidly since the Transplant Act became effective in 2000. This was because the families of suspected brain-dead patients took a passive attitude and waited for organ donation applications. There was a need to promote organ donation following brain death. As a result, two successive pilot projects were conducted to establish an organ procurement agency from 2007 [1] to 2008 [2].

In Korea, social interest in donation after brain death has increased owing to the donation by Choi Yo-Sam, a Korean world boxing champion, in 2008, and the corneal donation by Cardinal Kim Soo-Hwan in 2009. In 2010, the Korea Organ Donation Agency (KODA), the only Independent Organ Procurement Organization (IOPO) in Korea, was established, followed by the amendment to the Trans- 


\section{HIGHLIGHTS}

- The Donation Improvement Program (DIP) was introduced in Korea in 2012 and contributed to improving the perception of brain death and the donation rate after brain death.

- DIP was introduced in Korea in 2012 and contributed to improving the perception of brain death and the donation rate after brain death.

- If we receive national support with cooperation between organ procurement organizations and hospitals with potential brain-dead patients, we can improve donation in Korea.

plant Act in 2011 [3], to implement a system for reporting potential brain-dead patients [4]. This system informs the IOPO of a suspected potential brain-dead patient, which has created the motivation to discover potential braindead patients in medical institutions. Moreover, KODA laid the institutional foundation by introducing the Donor Action Program (DAP) in 2012 [5]. In April 2017, KODA was newly established by merging with the Korea Foundation for Human Tissue Donation and became the only IOPO and human tissue donation support organization in Korea.

The DAP is a quality management program developed and validated in Europe to promote organ donation after brain death. It was started by the Donor Action Working Group with the cooperation of the Eurotransplant International Foundation, International Foundation (The Netherlands), Organización Nacional de Trasplantes (Spain), and the Partnership for Organ Donation (USA) in 1994. The program checks the rate of potential brain-dead patients identified by physicians and investigates the reasons why potential brain-dead patients were not identified to improve organ donation [6].

A preliminary study to introduce the DAP in Korea was performed in 2009, which confirmed that changing the perception of physicians toward brain death through the DAP could contribute to an increase in organ donation following brain death [7]. As a result, KODA started to operate the DAP in 2012 with support from the government. After the end of the DAP in 2014, KODA modified it into the Donation Improvement Program (DIP) due to differences in the process of organ donation in Europe, where the patient needs to be declared brain-dead before the decision to donate is made, whereas, in Korea, brain death determination starts after the consent for donation. It was developed as an online system (www.dip-koda1458.kr) in 2015 and collected medical records of deceased patients from participating hospitals.

First, the Medical Record Review (MRR) entails a medical record survey of deceased patients in the intensive care units or emergency rooms included in the project. The medical record survey is usually performed by the in-hospital coordinator or the head nurse in the intensive care unit, and the person in charge decides through a meeting.

The survey entails a retrospective MRR that is performed from January 1 of the previous year to the day before the signing of the memorandum of understanding (MOU) and a prospective MRR that is performed after the date of the MOU. Collected data include demographic information, medical information, and the Glasgow Coma Scale score before death. Information on reporting to KODA, as well as approach status to family members with interviews on donations, obtaining verbal and written consent for donations, the process of declaring brain death, and managing donors was also collected and entered into the website. Through this data, we can see the percentage of potential brain-dead donors to total deaths (in hospitals), and extract statistics about the evaluation and reporting of potential brain-dead donors, interviews with potential brain-dead donors' families, and consent. The extracted data were used as a basis for identifying which stages in the donation process needed to be modified and improved at the participating hospitals.

The Hospital Attitude Survey (HAS) is a survey conducted on medical and administrative staff of hospitals to evaluate their knowledge, attitudes, skills, and reactions to organ donation after brain death and human tissue donation and to identify the need for education. The reason why administrative staff participate in the survey is to investigate their attitudes toward donation for former employees of medical institutions, and because the role of administrative staff is important in finding potential braindead donors in relatively small medical institutions.

KODA provides MRR and HAS results by holding 2-3 DIP committee (DIPC) sessions per year at hospitals participating in the DIP, and DIPC members (medical doctors, intensivists, nurses, and organ and tissue coordinators) serve as a supporting group by presenting various opinions to promote organ donation in the hospital. The number of participants in the DIPC is not fixed, and the participants are organized by the hospital itself.

In Korea, the number of donations after brain death 
continued to increase after the DIP began, and the number of deceased organ donors reached 573 in 2016. Korea was also the first country in Asia to surpass $11 \mathrm{pmp}$ : per million population [8]. In 2017, negative media reports related to donation became an issue, and the number of brain-dead donors decreased due to the spread of negative perceptions about donation. Other influences include the implementation of laws on withdrawing life-sustaining treatment. As a result, the imbalance between the supply and demand of organ transplants is expected to accelerate. To solve this problem, this study was conducted to review the performance of the DIP in Korea, describe the role and direction of the DIP in the future, and provide basic data for increasing transplantation.

\section{METHODS}

This study was exempted from deliberation by the Institutional Review Board of Seoul National University College of Medicine/Seoul National University Hospital (IRB No. 1702-089-831).

The data collected for this study included data on deceased patients from www.dip-koda1458.kr from 2012 to 2018. Among the HAS results implemented from 2012 to 2018 , the results were also compared and analyzed in 2012, 2015, and 2018. The MRR targeted all contracted hospitals, and the HAS survey subjects were neurosurgeons, neurologists, emergency medicine specialists, surgeons and intensive care unit staff, ward staff, emergency room nurses, hospital coordinators, social workers, and general administrative staff who wished to participate.
Participating hospitals were divided into secondary and tertiary hospitals, and university hospitals and non-university hospitals. The hospitals had 200 to 1,000 beds.

The HAS was modified to suit the domestic situation, and we received advice from a medical doctor after the annual revision. The implementation of the HAS is a matter included in the agreement with the hospital and they were notified in advance that it could be used for research purposes. The HAS questionnaire consists of multiple choice and short answer questions, and does not use a Likert scale. It has 30 questions.

\section{Medical Record Review}

The MRR consists of 39 questions in seven categories: general information (10 questions), medical information (7), mental state (5), referrals (1), approach (5), donation (4), and tissue donation (7). We investigated the MRR data of hospitals participating in the DIP, as follows: 4,149 cases (36 hospitals) in 2012, 6,857 cases (63 hospitals) in $2013,7,325$ cases (69 hospitals) in $2014,7,660$ cases (69 hospitals) in $2015,9,972$ cases (71 hospitals) in 2016, 10,898 cases ( 77 hospitals) in 2017 , and 11,524 cases ( 77 hospitals) in 2018. This study checked the total number of deaths and the number of potential brain-dead donors by year, and compared and analyzed the identification rates and donation rates. We also analyzed the cause of brain death and the distribution of deceased patients by age among the potential brain-dead donors. Data were analyzed by year and duration of participation.

\section{Hospital Attitude Survey}

The HAS consists of 30 questions: general characteristics (4 questions), basic awareness of organ and tissue

Table 1. Results of medical record review performed in 2012-2018

\begin{tabular}{lccccccc}
\hline \multirow{2}{*}{ Donation pathway } & \multicolumn{7}{c}{ Year (number of hospitals) } \\
\cline { 2 - 7 } & $2012(36)$ & $2013(63)$ & $2014(69)$ & $2015(69)$ & $2016(71)$ & $2017(77)$ & $2018(77)$ \\
\hline All death records & 4,149 & 6,857 & 7,325 & 7,660 & 9,972 & 10,898 & 11,524 \\
Medically available & 3,052 & 5,340 & 5,895 & 6,405 & 8,353 & 9,150 & 9,439 \\
Severe brain damage & 1,182 & 2,003 & 2,658 & 2,551 & 2,685 & 2,787 & 2,832 \\
Potential brain death & $1,182(28.5)$ & $1,682(24.5)$ & $1,845(25.2)$ & $1,798(23.5)$ & $1,827(18.3)$ & $1,924(17.7)$ & $2,013(17.5)$ \\
Identify & 275 & 507 & 989 & 1,087 & 1,228 & 1,306 & 1,297 \\
Referral & 92 & 262 & 790 & 914 & 1,115 & 1,143 & 1,147 \\
Approach & 272 & 432 & 715 & 774 & 842 & 878 & 840 \\
Consent & 90 & 177 & 227 & 293 & 371 & 337 & 311 \\
Donation & 86 & 169 & 201 & 239 & 291 & 281 & 259 \\
\hline
\end{tabular}

Values are presented as number or number (\%). 
donation (5), organ transplantation and donation status in the country (3), status of the donation and awareness of the DIP (6), brain death occurrence by the attitude of the estimator (6), organ procurement coordinator (2), and educational experience (4). In this study, we compared and analyzed the HAS results of physicians, nurses, and the administrative staff of 23 hospitals participating in the DIP in 2012, 51 hospitals in 2015, and 51 hospitals in 2018.

\section{RESULTS}

\section{Medical Record Review}

From 2012 to 2018, the total number of deaths in the intensive care units of hospitals participating in the DIP were as follows: 4,149 (2012), 6,857 (2013), 7,325 (2014), 7,660 (2015), 9,972 (2016), 10,898 (2017), and 11,524 (2018). Potential brain-dead donors showed a distribution of $21.0 \%$ among the total number of deaths (Table 1 ). The number of patients identified by medical teams as poten- tial brain-dead donors increased from 275 (23.3\%) in 2012 to $1,306(67.9 \%)$ in 2017 , but decreased to $1,297(64.4 \%)$ in 2018. The number of organ donors among potential brain-dead patients also increased annually from 86 (7.3\%) in 2012 to 291 (15.9\%) in 2016. However, the number decreased to 281 (14.6\%) in 2017 and 259 (12.9\%) in 2018, showing a decreasing trend from 2017 (Fig. 1).

As for the causes of brain death among potential brain-dead donors, cerebrovascular accidents decreased from $56.9 \%$ in 2012 to $48.8 \%$ in 2018 , and head trauma decreased from $31.1 \%$ in 2012 to $29.0 \%$ in 2018 , while hypoxic brain damage doubled from $7.0 \%$ in 2012 to $13.9 \%$ in 2018 (Supplementary Fig. 1). Also, the most common condition among the total number of donors was cerebrovascular accidents, which decreased from 50\% in 2012 to $39.8 \%$ in 2018 , while hypoxic brain damage increased from $14.0 \%$ in 2012 to $28.2 \%$ in 2018 (Fig. 2).

In addition, hypoxic brain damage showed the highest identification and donation rates of potential brain-dead donors (2012-2018), as the identification rate in 2018 was $78.5 \%$ and the donation rate was $26.2 \%$ (Supplementary
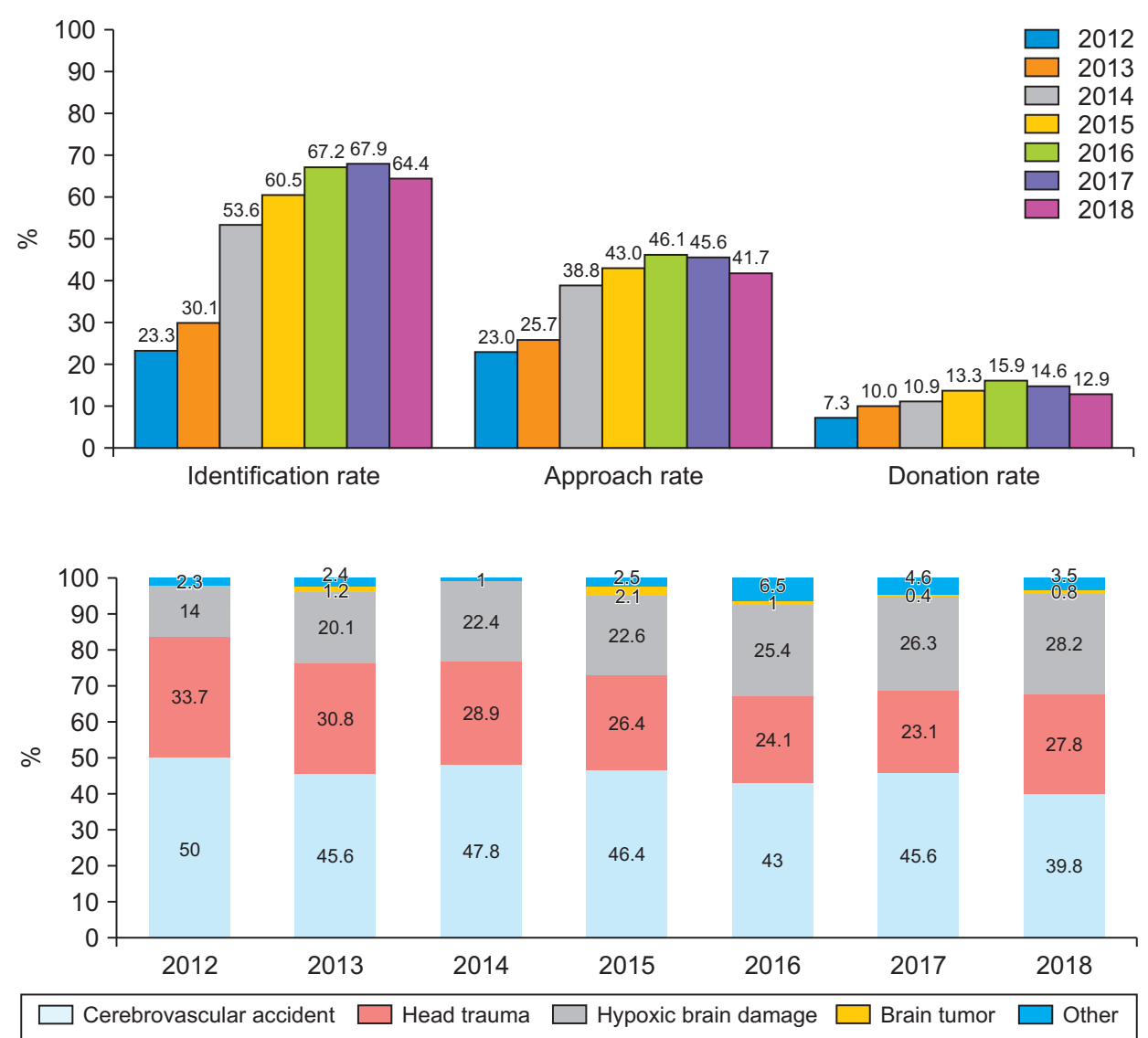

Fig. 1. Potential brain death identification, approach, and donation rates in 2012-2018.

Fig. 2. Causes of donations after brain death by year. 
Table 1). The most common age group among potential brain-dead donors was 50-59 years of age, having a proportion from 270 (22.8\%) to 467 (25.6\%) (Supplementary Fig. 2). Also, patients in their 50 s showed a high percentage among the total number of donors, representing $46(27.2 \%)$ in 2013, 92 (31.6\%) in 2016, and 81 (31.3\%) in 2018 (Supplementary Fig. 3), while those in their 40s showed the highest percentage at 26 (30.2\%) in 2012.

The potential brain-dead donor identification and donation rates differed according to age. According to the results from 2018 , the identification rate was more than $70 \%$ between the ages of 0 and 69 , but $53.7 \%$ were in their 70 s and $28.6 \%$ were in their $80 \mathrm{~s}$ and older. Teenagers had the highest donation rate of $25 \%$ in 2018 . As for other ages, 0-9 years was $7.1 \%, 70$ s were $5.7 \%$, and 80 s were $0.9 \%$ (Supplementary Table 2).

As a result of comparing the identification and donation rates of potential brain-dead donors, according to the DIP agreement, in the maintenance period the identification rate of potential brain-dead donors increased from $24.9 \%$ ( 6 months before the agreement) to $41.3 \%$ ( 6 months after the agreement), $51 \%$ (6-12 months after the agreement), $61.3 \%$ ( $1-2$ years after the agreement), and $73.2 \%(4-5$ years after the agreement). However, the rate decreased to $67.7 \%$ (5-6 years after the agreement) and $69.8 \%$ (6-7 years after the agreement). In addition, the donation rate increased significantly from $7.5 \%$ (6 months before the agreement) to $17.5 \%$ (2-3 years after the agreement) but decreased to $12.1 \%$ (5-6 years after the agreement) and $14.0 \%$ (6-7 years after the agreement) (Table 2).

\section{Hospital Attitude Survey}

This study conducted surveys of healthcare professionals, nurses, and the administrative staff of hospitals in 2012, 2015 , and 2018. The total number of participants was 1,075 in $2012,2,494$ in 2015 , and 3,600 in 2018 . The number of healthcare professional by year was 948 in 2012, 2,240 in 2015, and 3,217 in 2018 (Supplementary Fig. 4). In 2012 and 2015, most HAS survey participants had 6-10 years' experience, and in 2018, most employees had 1120 years' experience.

\section{General Attitude toward Brain Death}

The number of survey participants that answered "yes" to the question about whether they recognized brain death to be equivalent to death was as follows: $780(72.6 \%)$ in $2012,1,820(73.0 \%)$ in 2015 , and 2,606 (72.4\%) in 2018. This showed there was no difference in the respondents'

Table 2. Identification and donation rates of potential brain deaths according to the agreement maintenance period

\begin{tabular}{lcccccccccc}
\multicolumn{1}{c}{$\begin{array}{c}\text { Agreement } \\
\text { maintenance period }\end{array}$} & $\begin{array}{c}6 \text { Months } \\
\text { before }\end{array}$ & $\begin{array}{c}6 \text { Months } \\
\text { after }\end{array}$ & $\begin{array}{c}6-12 \text { Months } \\
\text { after }\end{array}$ & $\begin{array}{c}1-2 \text { Years } \\
\text { after }\end{array}$ & $\begin{array}{c}2-3 \text { Years } \\
\text { after }\end{array}$ & $\begin{array}{c}3-4 \text { Years } \\
\text { after }\end{array}$ & $\begin{array}{c}4-5 \text { Years } \\
\text { after }\end{array}$ & $\begin{array}{c}5-6 \text { Years } \\
\text { after }\end{array}$ & $\begin{array}{c}6-7 \text { Years } \\
\text { after }\end{array}$ \\
\hline Number of hospitals & 77 & 77 & 75 & 72 & 70 & 69 & 65 & 37 & 27 \\
Identification rate (\%) & 24.9 & 41.3 & 51.0 & 61.3 & 68.3 & 68.3 & 73.2 & 67.7 & 69.8 \\
Donation rate (\%) & 7.5 & 9.5 & 12.4 & 11.7 & 17.5 & 16.2 & 15.8 & 12.1 & 14.0 \\
\hline
\end{tabular}

Identification rating: identified as a potential brain death/PBD×100; donated rating: donated as a potential brain death/PBD $\times 100$.

PBD, potential brain death.

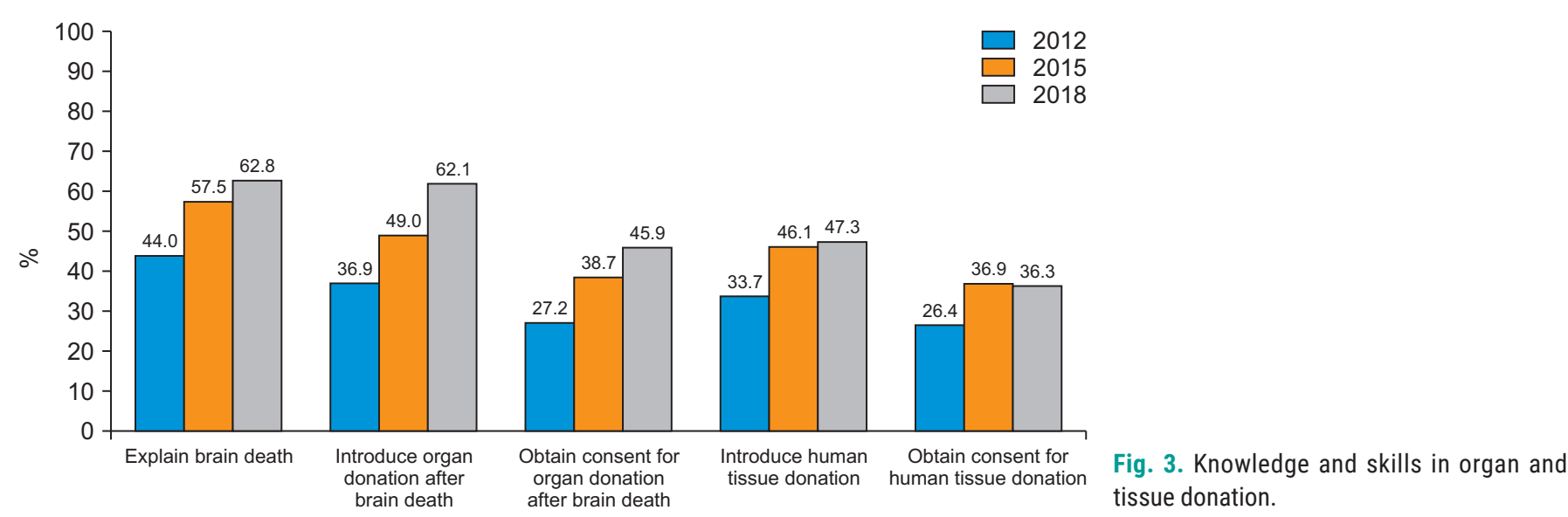




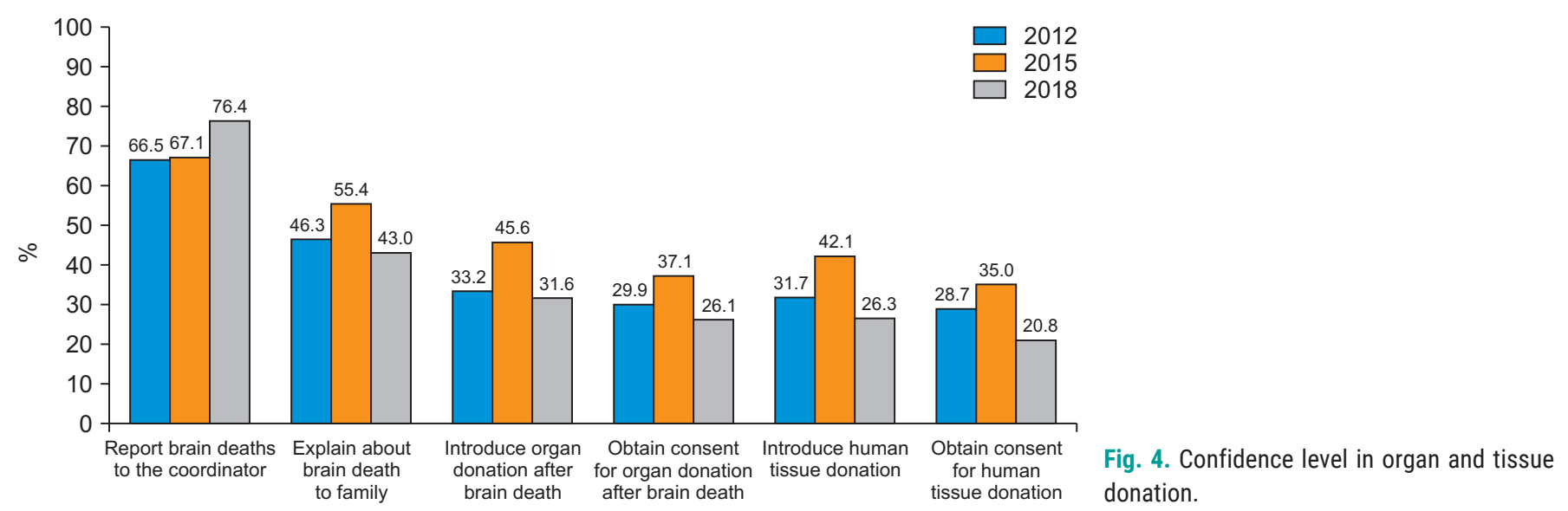

attitudes towards brain death by year. By occupational group, $83.0 \%-87.6 \%$ of physicians, $68.9 \%-69.6 \%$ of nurses, and $54.3 \%-60.6 \%$ of administrative staff recognized brain death as equivalent to death (Supplementary Table 3).

\section{Knowledge and Skills Required for Donation}

For the knowledge and skills required for donation, those who answered positively ("yes") that they had the knowledge and skills required to explain brain death to the patient's family increased from $473(44.0 \%)$ in 2012 to 1,433 (57.5\%) in 2015, and 2,261 (62.8\%) in 2018. Those who had the knowledge and skills to introduce donation after brain death increased from 397 (36.9\%) in 2012 to 1,222 $(49.0 \%)$ in 2015 , and $2,236(62.1 \%)$ in 2018 . Those who had the knowledge and skills required to obtain consent to donate after brain death increased from $292(27.2 \%)$ in 2012 to 966 (38.7\%) in 2015, and 1,651 (45.9\%) in 2018. Those who had the knowledge and skills to introduce human tissue donation also increased from $362(33.7 \%)$ in 2012 to $1,149(46.1 \%)$ in 2015, and 1,702 (47.3\%) in 2018 (Fig. 3).

\section{Confidence Level Related to Donation}

The number of participants that believed that they could freely report brain deaths to the donation coordinator increased from $715(66.5 \%)$ in 2012 to $1,674(67.1 \%)$ in 2015 , and 2,751 (76.4\%) in 2018. However, participants expressed discomfort about explaining brain death and introducing organ and human tissue donation to family members. This was evidenced by the number of participants who were confident about explaining brain death to family members decreasing from 498 (46.3\%) in 2012 to $1,548(43.0 \%)$ in 2018 . With respect to introducing organ donation after brain death, the number decreased from
$357(33.2 \%)$ in 2012 to $1,138(31.6 \%)$ in 2018 . In terms of introducing human tissue donation, the number decreased from 341 (31.7\%) in 2012 to 948 (26.3\%) in 2018 (Fig. 4).

\section{DISCUSSION}

Although Korea was the first country in Asia to surpass 11 pmp per year in deceased-person donations, the number is still much lower than that of developed countries that have advanced organ donation practices, such as the United States or Spain. Also, the number of donations after brain death in Korea had declined as of 2017, and is becoming a national issue. This was the point at which 5 years have passed since the DIP was initiated. It is judged that a negative national atmosphere has influenced the identification and donation rates.

Therefore, the purpose of this study was to review the performance of the DIP, which was introduced by KODA in 2012 to promote organ donation, and to explore ways to increase brain death organ transplantations by describing the role and direction of the DIP in the future. In Korea, the failure to identify potential brain-dead patients was confirmed as the main obstacle to organ donation after brain death [7]. To solve this problem, reporting of presumed brain-dead patients was implemented under Article 17 of the Transplant Act from June 2011 [4]. Moreover, hospitals participating in the DIP prepared a simplified standard for reporting potential brain-dead patients as determined by the DIPC and designated a DIP link to reduce the burden on healthcare professionals with respect to reporting potential brain-dead patients. Identifying potential brain-dead patients as organ donors has a direct link to referrals [7]. 
Thus, the early stage of the DIP was focused on increasing the identification rate of potential brain-dead patients. As a way to increase the identification rate, the DIPC discussed the reasons why potential brain-dead donors were not identified or reported, and prepared solutions to the challenges that may arise in the process of organ donation.

Solutions included unifying the potential brain-dead patient notification system and expanding the opportunity for IOPO coordinators to meet the patient's family. Hospitals participating in the DIP also focused on educating their healthcare professionals. Education mainly consisted of group education and one-on-one education. As a result, the identification rate for potential brain-dead patients increased from $23.3 \%$ in 2012 to $67.9 \%$ in 2017 , but decreased to $64.4 \%$ in 2018 . The donation rate also increased to $15.9 \%$ in 2016 from $7.3 \%$ in 2012, which was the early stage of the DIP's implementation. However, the rate decreased from $14.6 \%$ in 2017 to $12.9 \%$ in 2018 . Therefore, the increase in donations after brain death was very low compared to the number of patients waiting for transplantations $(39,405$ as of 2019), which is growing exponentially year after year. As a result of examining all cases of brain death reported to KODA in 2019, refusal by family members was the most significant and frequent barrier to organ donation [9]. According to a study by Ghorbani et al. [10] and reports on potential brain-dead patients made to KODA in 2013 and 2018 [11], the specific reasons for objecting to organ donation were the family members' denial of a brain death diagnosis and demands for aggressive treatment. This means that improving families' understanding of brain death is a key factor of organ donation [12], and that the role of the healthcare professionals interviewing the family members of potential braindead patients is of utmost importance. In addition, it is necessary to change the national atmosphere and people's perceptions, so that they accept organ donation as a part of death. For this, public relations at the national level are necessary, and public service advertisements would be helpful.

An organ procurement organization (OPO) has various roles and responsibilities. An OPO is notified of potential brain-dead donors and potential tissue donors that occur nationwide. In addition, it is in charge of managing brain death donors and the families of human tissue donors. Other duties include discussing plans with healthcare professionals who interview the families of potential braindead patients, conducting such interviews, and providing information and counseling on organ donation [13].
However, counseling for potential brain-dead patients' family members is not available at all hospitals nationwide, only at hospitals that link counseling to OPO coordinators. According to a report, family members are more likely to agree to organ donation when interviewed by an OPO coordinator than by a healthcare professional $[14,15]$. That is, family members are likely to accept organ donation more objectively under two circumstances. The first is when the healthcare professional explains the medical condition so that the family members can recognize that brain death is equivalent to death. The second is when KODA, the OPO in Korea, in a neutral position and with a public purpose, conducts the organ donation interviews.

In addition, as a result of analyzing the causes of brain deaths in this study, the percentage of cerebrovascular accidents was found to have decreased, while the percentage of hypoxic brain damage and cardiac arrest increased, with the percentage of patients with hypoxic brain damage increasing from $14.0 \%$ in 2012 to $28.2 \%$ in 2018 . According to the HAS results, $72.6 \%$ of respondents in 2012 and $72.4 \%$ in 2018 answered "yes" when asked whether they considered brain death equivalent to death. Compared to the preliminary study that introduced the DAP in Korea, where the overall average of positive responses that considered brain death equivalent to death was 55.5\% [7], the perceptions and attitudes of healthcare professionals and administrative staff toward brain death have shifted positively. On the other hand, according to a 2010 study on 11 countries using the Donor Action database, the general attitude toward brain death was more negative than in Norway (94.7\%) and Belgium (89.7\%) [16].

In light of the negative perceptions, we need to increase awareness of brain death among medical and administrative staff. For this purpose, we need to continue educating healthcare professionals. We must also consider introducing a legal system that recognizes brain death as death. While there was no difference in the educational experience and needs of the respondents by year, there were differences in their knowledge and skills. Those who answered positively ("yes") that they wanted the knowledge and skills necessary to introduce donation after brain death increased significantly from $36.9 \%$ in 2012 to $62.1 \%$ in 2018. Also, positive responses about the knowledge and skills to introduce human tissue donation increased from $33.7 \%$ (2012) to $47.3 \%$ (2018), and those regarding the knowledge and skills to explain brain death increased from $44.0 \%$ (2012) to $62.8 \%$ (2018). This is considered the result of conducting active training for medical personnel 
after the introduction of the DIP. However, the knowledge and skills healthcare professionals need to obtain consent for human tissue donation showed the least improvement. Therefore, in addition to continuous promotion and training for medical personnel, we need to improve their knowledge and skills related to organ and human tissue donation after brain death and the skills to interview family members through education including workshops.

This study attempted to verify how effective the introduction of the DIP in Korea was with respect to improving the recognition of potential brain-dead patients as organ donors and the knowledge and skills related to the recognition and donation of potential brain-dead patients. The DIP was effective at increasing the identification and donation rates of potential brain-dead patients as of 2016 compared to 2012, when the DIP was first introduced. Moreover, MRR was an effective tool to assess the trends of potential brain-dead donors in hospitals. In addition, active training after the DIP agreement resulted in positive changes in the perceptions and attitudes of medical and administrative staff toward brain death and donation. The training also helped improve their knowledge, skills, and experience.

However, as hospitals recruit new employees every year, we need to promote and educate healthcare professionals continuously. In the future, the direction of the DIP in Korea should focus on preparing plans to increase interviews for family members about organ donation, increase the rates of consent and donation in proportion to the number of interviews conducted, and develop and supplement professional and systematic educational contents.

The MRR data in this study were for all DIP-conventional hospitals. However, there is a limitation that it was not the total death data of the hospitals and the HAS data did not come from a survey conducted with the same subjects every year. Therefore, we propose a follow-up study that can compare changes in perceptions and attitudes about donation by year by expanding the MRR nationwide and implementing the HAS for the same person.

\section{ACKNOWLEDGMENTS}

\section{Conflict of Interest}

No potential conflict of interest relevant to this article was reported.

\section{ORCID}

Su Jin Heo

Yong Ho Ju

Eun Jeong Noh

Kyoung Min Kim

Yu Kyoung Son

Sun Woo Jung

Hyun Jin Kang

Jung Rim Lee

Won Hyun Cho

Jongwon $\mathrm{Ha}$

https://orcid.org/0000-0001-8846-4122 https://orcid.org/0000-0003-1566-7476 https://orcid.org/0000-0003-0380-5501 https://orcid.org/0000-0001-7958-3963 https://orcid.org/0000-0002-6444-3930 https://orcid.org/0000-0002-7697-7534 https://orcid.org/0000-0002-4164-1387 https://orcid.org/0000-0001-6038-5115 https://orcid.org/0000-0001-5916-6601 https://orcid.org/0000-0003-2285-3517

\section{Author Contributions}

Conceptualization: SJH, HJK, JH. Data curation: SJH, YHJ, EJN, KMK, YKS, SWJ. Formal analysis: SJH, HJK, JRL, WHC, JH. Funding acquisition: WHC, JH. Methodology: HJK, JRL, JH. Project administration: SJH, HJK, JH. Visualization: YHJ, EJN, KMK, YKS, SWJ. Writing-original draft: SJH, HJK, JH. Writing-review \& editing: WHC, JH.

\section{Supplementary Materials}

Supplementary materials can be found via https://doi. org/10.4285/kjt.21.0006.

\section{REFERENCES}

1. Cho WH, Kim HT, Lee HJ, Seo YM, Lee SD, Son El, et al. Development of Korean model for independent organ procurement organization. J Korean Soc Transplant 2008;22:109-19.

2. Park YJ, Kang H, Kim EM, Shin WY, Yi N, Suh K, et al. Establishment of active identification and management system for potential brain dead donors in life-link center. J Korean Soc Transplantation 2009;23:43-51.

3. Kim HC, Kim HW. The issues and suggestions of organ transplant in Korea. Ewha Law J 2013;17:225-51.

4. Gil E, Park JB. Optimal management of brain death donor. J Korean Soc Transplant 2015;29:89-100.

5. Lee YJ. Activation policy for brain-dead organ donation. Ewha Med J 2015;38:1-6.

6. Wight C, Cohen B, Roels L, Miranda B. Donor action: a quality assurance program for intensive care units that increases organ donation. J Intensive Care Med 2000;15:104-114.

7. Park SJ, Yoon YC, Cho WH, Roels L, Smits J, Cohen B, et al. Preliminary results of donor Action in Korea. $J$ 
Korean Soc Transplant 2012;26:101-11.

8. International Registry on Organ Donation and Transplantation (IRODaT). 2016 Newsletter [Internet]. Seoul: IRODaT; 2016 [cited 2021 Jun 10]. Available from: https://www.irodat.org/.

9. Korea Organ Donation Agency (KODA). 2019 Annual report [Internet]. Seoul: KODA; 2019 [cited 2021 Jun 10]. Available from: http://koda1458.kr.

10. Ghorbani F, Khoddami-Vishteh HR, Ghobadi O, Shafaghi S, Louyeh AR, Najafizadeh K. Causes of family refusal for organ donation. Transplant Proc 2011;43:405-6.

11. Korea Organ Donation Agency (KODA). Notification of potential brain death 2013-2018. Seoul: KODA; 2019.

12. Vincent $A$, Logan $\mathrm{L}$. Consent for organ donation. $\mathrm{Br} \mathrm{J}$ Anaesth 2012;108 Suppl 1:i80-7.

13. Kim MG, Jeong JC, Cho EJ, Huh KH, Yang J, Byeon NI, et al. Operational and regulatory system requirements for pursuing self-sufficiency in deceased donor organ transplantation program in Korea. J Korean Soc Transplant 2010;24:147-58.

14. Lenzi JA, Sarlo R, Assis A, Ponte M, Paura P, Araújo C, et al. Family informed consent to organ donation--who performs better: organ procurement organizations, in-hospital coordinators, or intensive care unit professionals? Transplant Proc 2014;46:1672-3.

15. Rodrigue JR, Cornell DL, Howard RJ. Organ donation decision: comparison of donor and nondonor families. Am J Transplant 2006;6:190-8.

16. Roels L, Spaight C, Smits J, Cohen B. Critical care staffs' attitudes, confidence levels and educational needs correlate with countries' donation rates: data from the Donor Action database. Transpl Int 2010;23:842-50. 